\title{
TO COMPARE THE ANALGESIC EFFICACY OF 0.25\% BUPIVACAINE AND 0.25\% ROPIVACAINE IN TAP BLOCK AS A PART OF A MULTIMODAL ANALGESIA REGIMEN FOR POST CAESAREAN DELIVERY PAIN MANAGEMENT
}

\author{
Meghna Maheshwari¹, Vimal Dangi'2, Sadhana Sanwatsarkar³, Janki Singh ${ }^{4}$
}

${ }^{1}$ Senior Resident, Department of Anaesthesiology, Sri Aurobindo Medical College and PG Institute, Indore, M. P.

${ }^{2}$ Final Year Postgraduate Student, Department of Anaesthesiology, Sri Aurobindo Medical College and PG Institute, Indore, M. P. ${ }_{3}^{3}$ HOD, Department of Anaesthesiology, Sri Aurobindo Medical College and PG Institute, Indore, M. P.

${ }^{4}$ Associate Professor, Department of Anaesthesiology, Sri Aurobindo Medical College and PG Institute, Indore, M. P.

\section{BACKGROUND}

ABSTRACT

Women having a caesarean delivery present a unique set of challenges to the Anaesthetist postoperatively. They need to be alert, comfortable and ambulant in order to care for their newborn.[1] As part of a multimodal analgesic regimen, Opioids and NSAIDs are required initially to achieve effective analgesia.

This study is intended to evaluate the analgesic efficacy of $0.25 \%$ Bupivacaine and $0.25 \%$ Ropivacaine in TAP block as a part of multimodal analgesia regimen over the first 24 postoperative hours after lower segment caesarean section.

\section{MATERIALS AND METHODS}

In a prospective, randomised, controlled, double-blinded study sixty parturient of American Society of Anesthesiologist's (ASA) physical status I and II undergoing lower segment caesarean section were randomised to undergo a bilateral TAP block with Bupivacaine $0.25 \%$ (Group $A=30$ ) and Ropivacaine 0.25\% (Group B=30). In addition, all patients received standard analgesic injection tramadol $2 \mathrm{mg} / \mathrm{kg}$ and IV injection diclofenac $75 \mathrm{mg}$ as required in the postoperative period. All patients received standard spinal anaesthesia and TAP block was performed at the end of surgery. Each patient was assessed after operation at 2, 4, $6,12,24$ hours after surgery in postoperative period.

\section{RESULTS}

The mean visual analogue scale (VAS) score of Group A was less than mean VAS score of Group B at all-time interval, but was not statistically significant ( $p>0.05$ ). The mean time to first rescue analgesia in Group A was $434.166 \pm 213.035$ min and in Group B it was $436.875 \pm 170.229 \mathrm{~min}$, which was not significant statistically $(\mathrm{p}>0.05)$.

\section{CONCLUSION}

Transversus abdominis plane block holds considerable promise as part of a multimodal analgesic regimen for post caesarean delivery analgesia. The conclusion of our study is that $0.25 \%$ Bupivacaine and $0.25 \%$ Ropivacaine are equally effective in TAP block and provides effective postoperative analgesia.

\section{KEYWORDS}

Analgesia, Lower Segment Caesarean Section, Transversus Abdominis Plane Block.

HOW TO CITE THIS ARTICLE: Maheshwari M, Dangi V, Sanwatsarkar S, et al. To compare the analgesic efficacy of $0.25 \%$ bupivacaine and $0.25 \%$ ropivacaine in tap block as a part of a multimodal analgesia regimen for post caesarean delivery pain management. J. Evolution Med. Dent. Sci. 2018;7(09):1071-1074, DOI: 10.14260/jemds/2018/244

\section{BACKGROUND}

Women having a Caesarean delivery present a unique set of challenges to the Anaesthetist postoperatively. They need to be alert, comfortable and ambulant in order to care for their newborn.[1] As part of a multimodal analgesic regimen, Opioids and NSAIDs are required initially to achieve effective analgesia. However, opioids are associated with dosedependent side-effects including nausea, vomiting, pruritus, sedation and respiratory depression. ${ }^{[2,3]}$ NSAIDs also have certain side effects like haemostasis alteration, renal dysfunction, gastrointestinal haemorrhage etc. Techniques that reduce opioids and NSAIDs requirements may be of benefit in this population.

'Financial or Other Competing Interest': None. Submission 17-01-2018, Peer Review 01-02-2018,

Acceptance 17-02-2018, Published 26-02-2018.

Corresponding Author:

Dr. Vimal Dangi,

\#728, Premium Park, Indore, M. P.

E-mail: drvimaldangi@gmail.com

DOI: $10.14260 /$ jemds $/ 2018 / 244$

\section{(c) (1) $(9)$}

Transversus abdominis plane block (TAP block) ${ }^{[4,5]}$ is a regional technique where abdominal wall neural afferents are blocked by depositing local anaesthetic into the neurofascial plane between internal oblique and transversus abdominis muscle.[4,5] It is gaining popularity as an alternative to subarachnoid opioids due to fewer side effects and the ease and accuracy of administration. The present study is designed to compare the postoperative analgesic efficacy of both drugs $0.25 \%$ Bupivacaine and $0.25 \%$ Ropivacaine when used as a component of a multimodal analgesic regimen.

Aims and Objectives-

To compare the analgesic efficacy of TAP $0.25 \%$ Bupivacaine and $0.25 \%$ Ropivacaine over first 24 hours after lower segment caesarean section.

\section{MATERIALS AND METHODS}

The present study was undertaken in indoor patients admitted in Sri Aurobindo Medical College and PG Institute, Indore. After obtaining Institutional Ethics Committee approval and informed consent, 60 parturients of American 
Society of Anesthesiologist's (ASA) physical status I and II undergoing lower segment caesarean section were enrolled for study. A detailed pre-anaesthetic check-up was carried out before the surgery. Patients with history of drug allergy and local anaesthetic toxicity, bleeding diathesis, infection at the site of block, peripheral neuropathy, BMI $>35 \mathrm{~kg} / \mathrm{m}^{2}$, pregnancy wt. $<50 \mathrm{~kg}$ were excluded.

The recruited patients were randomly assigned to one of the two groups on the basis of computer-generated random number table, concealed in opaque envelop which was opened just before caesarean section. The patients in Group A received TAP block with $20 \mathrm{~mL} \quad 0.25 \%$ Bupivacaine and Group B $20 \mathrm{~mL}$ of $0.25 \%$ Ropivacaine per side.

In the operating room standard monitoring including electrocardiogram, non-invasive blood pressure and arterial oxygen saturation were used throughout. Patients were premedicated with intravenous Ranitidine and intravenous Ondansetron. Patients were pre-loaded with $500 \mathrm{~mL}$ of Ringer Lactate.

All patients received a standardised spinal anaesthesia with $0.5 \%$ hyperbaric Bupivacaine $2.2 \mathrm{~mL}$ without any additive in lateral position without any table tilt. Level of analgesia achieved was noted. Assessment of block was done by pinprick. Target height was T4. Patients were monitored intraoperatively. Hypotension was taken as fall in systolic blood pressure $>30 \%$ of baseline and was treated with incremental doses of Ephedrine $0.3 \mathrm{mg}$ and bolus of $200 \mathrm{~mL}$ of Ringer Lactate. Bradycardia was taken as heart rate $<60$ beats per minute and treated accordingly with intravenous Atropine $0.6 \mathrm{mg}$. No analgesic or sedation was given to any patient intraoperatively.

At the end of surgery Petit's triangle was identified on the side of surgery as a defect above the iliac crest between the fibres of external oblique and latissimus dorsi muscles. Under all aseptic precautions, the block was given through Petit's triangle with 22-G hypodermic needle attached to a $20 \mathrm{~mL}$ syringe containing the drug as per the group allocation. Needle was introduced perpendicular to skin and advanced until two "POPS" or "give way" were felt. Then the drug was deposited in the fascial plane after aspiration, check aspiration was done every $5 \mathrm{~mL}$ to rule out intravascular injection. The patient was observed for 15 minutes and then shifted to post-anaesthesia care unit.

The anaesthesiologist who observed the patients in PACU was blinded to the drug injected in TAPB. Patient was monitored every 5 minutes for half an hour, then every 15 minutes till 2 hours and then at 4, 6, 12, 24 hours postoperatively for pulse rate, systolic and diastolic blood pressure and respiratory rate, pain and complications if any. Pain was assessed according to visual analogue score from 0 to 10. Patient was given rescue analgesia in the form of intravenous Tramadol $2 \mathrm{mg} / \mathrm{kg}$ and Intravenous Diclofenac $75 \mathrm{mg}$ at a visual analogue pain score of 4 (i.e. minimal pain). Recession of motor block was noted by movement of ankle and knee joint and that of sensory block by pin prick on the opposite side of block.
The duration of analgesia in TAPB was considered to be from the time of recession of sensory level below T10 side to pain score of 4 (i.e. minimal pain). Patient was also observed for any other postoperative complications like haematoma, flank fullness, etc. At the end of study, data were pooled and analysed using SPSS version 17 and GraphPad version 5 and conclusion was drawn regarding the effectiveness of TAPB in postoperative analgesia and relative efficacy of the two drugs. The demographic variables were analysed using Fisher's exact test and student $\mathrm{t}$-test for parametric data.

Sample size was determined prospectively using data from previous caesareans performed under spinal anaesthesia in our institution (mean \pm standard deviation 48 $\mathrm{h}$ consumption of tramadol $260 \pm 50 \mathrm{mg}$ ). We considered $30 \%$ reduction in PCA tramadol in $48 \mathrm{~h}$ as a clinically significant end point. Based on this, power analysis indicated a minimum of 30 patients per group $(\alpha=0.05, \beta=0.2)$.

\section{RESULTS}

Sixty patients were entered into the study. 30 were randomised to undergo TAP blockade with $0.25 \%$ Bupivacaine and 30 with $0.25 \%$ Ropivacaine. All patients underwent Lower Segment Caesarean Section. All groups were comparable in age, weight and height (Table 1).

The mean age (mean \pm S.D.) in Group A was $25.7 \pm 3.03$ yrs. and in Group B was $25.2 \pm 4.373$ yrs. The groups were comparable in terms of age $(\mathrm{p}=0.60)$.

The mean height was $158.33 \pm 5.005 \mathrm{~cm}$ in Group A and $157.60 \pm 5.506 \mathrm{~cm}$ in Group B. The groups were comparable in terms of height $(\mathrm{p}=0.591)$.

The mean weight was $62.40 \pm 5.15 \mathrm{~kg}$ and $62.13 \pm 5.17 \mathrm{~kg}$ respectively in Group A and Group B, which was not statistically significant $(\mathrm{p}=0.842)$.

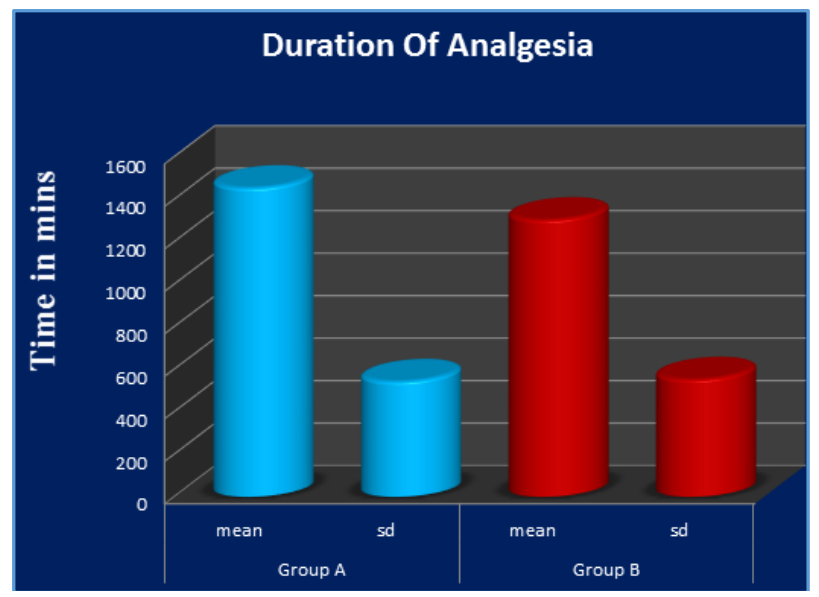

Figure 1. The Mean Duration of Analgesia was 1454.266 (24 hrs.) minutes with Standard Deviation of \pm 542.798 (9 hrs.) in Group A and 1303.833 (22 hrs.) minutes with a Standard Deviation of \pm 552.447 (9 hrs. 20 minutes) in Group B which was Insignificant. P value was $>0.05$ (Figure 1) 


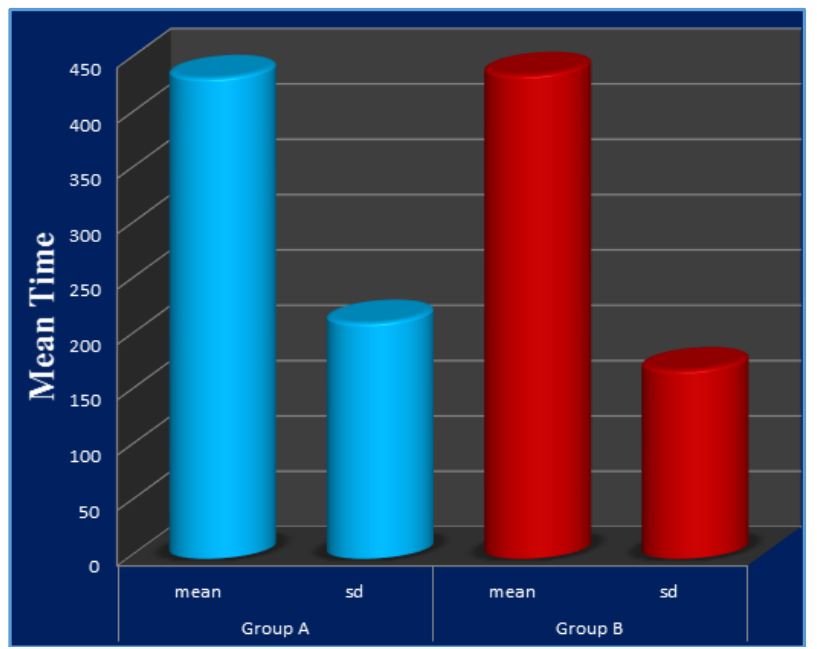

Figure 2. The Mean Time to First Rescue Analgesia in Group $A$ was $434.166 \pm 213.035$ min and in Group $B$ it was $436.875 \pm 170.229$ min which was not significant Statistically $(p>0.05)$ (Figure 2)

\begin{tabular}{|c|c|c|c|}
\hline Characteristic & Group A & Group B & P Value \\
\hline Mean Age (yrs.) & $25.7\{+/-3.03\}$ & $\begin{array}{c}25.2 \\
\{+/-4.37\}\end{array}$ & 0.60 \\
\hline Mean Height (cm) & $\begin{array}{c}158.33 \\
\{+/-5.005\}\end{array}$ & $\begin{array}{c}157.60 \\
\{+/-5.506\}\end{array}$ & 0.591 \\
\hline Mean Weight (kg) & $\begin{array}{c}62.40 \\
\{+/-5.15\}\end{array}$ & $\begin{array}{c}62.13 \\
\{+/-5.17\}\end{array}$ & 0.842 \\
\hline \multicolumn{4}{|c|}{ Table 1 } \\
\hline
\end{tabular}

The mean VAS score in Group A at 30 minutes, 2, 4, 6, 12 and 24 hours were $0.33 \pm 0.88,0.66 \pm 1.09,0.86 \pm 1.27,1.1 \pm$ $1.47,0.9 \pm 1.29$ and $0.3 \pm 0.74$ respectively.

The mean VAS score in Group B at 30 minutes, 2, 4, 6, 12 and 24 hours were $0.36 \pm 0.88,0.93 \pm 1.08,1.40 \pm 1.35,1.83 \pm$ $1.44,1.26 \pm 1.22$ and $0.7 \pm 0.91$ respectively.

The difference in mean VAS score was less at all-time interval in Group A, but was not significant, $(p>0.05)$ (Table 2).

The comparison of VAS scores at different time interval in both groups showed that TAP block has equal analgesic effects with Bupivacaine and Ropivacaine.

6 patients in Bupivacaine group and 8 patients in Ropivacaine group required rescue analgesia during first 12 hours.

\begin{tabular}{|c|c|c|c|c|c|c|}
\hline $\begin{array}{c}\text { VAS } \\
\text { (Mean } \pm \\
\text { S.D.) }\end{array}$ & $\mathbf{3 0}$ Mins & $\begin{array}{c}\mathbf{2} \\
\text { Hrs. }\end{array}$ & $\begin{array}{c}\mathbf{4} \\
\text { Hrs. }\end{array}$ & $\begin{array}{c}\mathbf{6} \\
\text { Hrs. }\end{array}$ & $\begin{array}{c}\mathbf{1 2} \\
\text { Hrs. }\end{array}$ & $\begin{array}{c}\mathbf{2 4} \\
\text { Hrs. }\end{array}$ \\
\hline Group A & $0.33 \pm$ & $0.66 \pm$ & $0.86 \pm$ & $1.1 \pm$ & $0.9 \pm$ & $0.3 \pm$ \\
& 0.88 & 1.09 & 1.27 & 1.47 & 1.29 & 0.74 \\
\hline Group B & $0.36 \pm$ & $0.93 \pm$ & $1.40 \pm$ & $1.83 \pm$ & $1.26 \pm$ & $0.7 \pm$ \\
& 0.88 & 1.08 & 1.35 & 1.44 & 1.22 & 0.91 \\
\hline P value & 0.88 & 0.34 & 0.12 & 0.055 & 0.26 & 0.06 \\
\hline \multicolumn{7}{|c|}{ Table 2 } \\
\hline
\end{tabular}

The mean duration of analgesia was 1454.266 (24 hrs.) minutes with standard deviation of \pm 542.798 ( 9 hrs.) in Group A and 1303.833 (22 hrs.) minutes with a standard deviation of \pm 552.447 ( 9 hrs. 20 minutes) in Group B, which was insignificant. P value was $>0.05$ (Figure 1).

The mean time to first rescue analgesia in Group A was $434.166 \pm 213.035 \mathrm{~min}$ and in Group B it was $436.875 \pm$
170.229 min which was not significant statistically $(\mathrm{p}>0.05)$ (Figure 2).

The difference between the mean pulse rate and mean systolic and diastolic blood pressure were found to be statistically non-significant between Group A and Group B at all periods of time. Thus, the effect of Bupivacaine and Ropivacaine on the pulse rate, mean arterial pressure and respiratory rate was found to be comparable suggesting that Bupivacaine and Ropivacaine have comparable haemodynamic stability in TAP block. In our study, we did not encounter any complication that could be attributable to the procedure or the drugs under study.

\section{DISCUSSION}

- The principal finding of our study is that $0.25 \%$ bupivacaine and $0.25 \%$ ropivacaine are equally effective in TAP block and provides effective postoperative analgesia in patients undergoing Lower Segment Caesarean Section.

- Our study data were comparable in both the groups in terms of demographic data, post-op analgesia, VAS score, nausea/ vomiting or any other side effects.

- We have found the superiority of TAP block in providing immediate postoperative analgesia reflected by a lower VAS score. Our finding is consistent with McDonnell et al[5] who found that TAP block as a component of a multimodal analgesic regimen provided superior analgesia when compared with placebo block up to 48 postoperative hours after elective caesarean delivery. Carney et $\mathrm{al},{ }^{[6]}$ in total abdominal hysterectomy found that anatomical TAP block significantly reduces postoperative pain scores up to $48 \mathrm{~h}$ period. Similar to our study Kocum A and Turkoz A et al[7] also compared efficacy of Ropivacaine $0.25 \%$ and Bupivacaine $0.25 \%$ in Lumbar Plexus and Sciatic Nerve Block and found that Ropivacaine $0.25 \%$ and Bupivacaine $0.25 \%$ are equally efficacious in providing analgesia as well as surgical anaesthesia. Further, the blockade achieved by either drug was of similar quality and provided similar duration of postoperative analgesia.

- Sforza et al also studied the effect of TAP blocks on patients in the first 12 hours following abdominoplasty and reported significant postoperative morphine sparing, improved pain scores and earlier ambulation in the TAP block group $(n=14)$ versus controls $(n=14)$. [8]

- Recently, Sharma et al[9] also found that TAP block by landmark technique improves VAS score in first $24 \mathrm{~h}$ in patients undergoing major abdominal surgery. Petersen et al[10] in 2012 also found that US guided bilateral TAP block in patients undergoing laparoscopic cholecystectomy provides superior postoperative pain scores.

\section{CONCLUSION}

From our study it can be concluded that-

1. $0.25 \%$ bupivacaine and $0.25 \%$ ropivacaine are equally effective in TAP block and provides effective postoperative analgesia.

2. Both the groups are comparable in demographic data and other parameters of our study. 
3. This block helps to facilitate early ambulation, infant care and minimum side effects for mother and child.

4. Studies have shown that the consumption of intravenous opioids has been reduced with use of this block, resulting in fewer opioid-mediated side effects.

\section{REFERENCES}

[1] Leung AY. Postoperative pain management in obstetric anesthesia--new challenges and solutions. J Clin Anesth 2004;16(1):57-65.

[2] Gadsden J, Hart S, Santos AC. Post-cesarean delivery analgesia. Anesth Analg 2005;101(5 Suppl):S62-9.

[3] Urbanczae L. Transverse abdominis plane block. Anesth Intensive Ther 2009;35:137-41.

[4] Rafi AN. Abdominal field block: a new approach via the lumbar triangle. Anaesthesia 2001;56(10):1024-6.

[5] McDonnell JG, O'Donnell B, Curley G, et al. The analgesic efficacy of transversus abdominis plane block after abdominal surgery: a prospective randomized controlled trial. Anesth Analg 2007;104(1):193-7.
[6] Carney J, Finnerty 0, Rauf J, et al. Ipsilateral transversus abdominis plane block provides effective analgesia after appendectomy in children: a randomized controlled trial. Anesth Analg 2010;111(4):998-1003.

[7] Kocum A, Turkoz A, Bozdogan N, et al. Femoral and sciatic nerve block with $0.25 \%$ bupivacaine for surgical management of diabetic foot syndrome: an anaesthetic technique for high-risk patients with diabetic nephropathy. J Clin Anesth 2010;22(5):363-6.

[8] Sforza M, Andjelkov K, Zaccheddu R, et al. Transversus abdominis plane block anesthesia in abdominoplasties. Plast Reconstr Surg 2011;128(2):529-35.

[9] Sharma P, Chand T, Saxena A, et al. Evaluation of postoperative analgesic efficacy of transverses abdominis plane block after abdominal surgery: a comparative study. J Nat Sci Biol Med 2013;4(1):17780.

[10] Petersen PL, Stjernholm P, Kristiansen VB, et al. The beneficial effect of transversus abdominis plane block after laparoscopic cholecystectomy in day-case surgery: a randomized clinical trial. Anesth Analg 2012;115(3):527-33. 